\title{
NT-proBNP AND BNP VALUES IN CARDIAC PATIENTS WITH DIFFERENT DEGREE OF LEFT VENTRICULAR SYSTOLIC DYSFUNCTION
}

\author{
Karel Kotaska ${ }^{\mathrm{a}}$, Jana Popelova ${ }^{\mathrm{b}}$, Marie Tiserova ${ }^{\mathrm{d}}$, Peter Telekes ${ }^{\mathrm{c}}$, Marie Vrzanova ${ }^{\mathrm{d}}$, \\ Jiri Bronsky ${ }^{a}$, Milada Halacova ${ }^{a}$, Jiri Kukacka ${ }^{a}$, Richard Prusa ${ }^{a}$ \\ a Department of Clinical Biochemistry and Pathobiochemistry, $2^{\text {nd }}$ Medical Faculty, Charles University, Faculty Hospital \\ Motol, Prague, Czech Republic \\ ${ }^{b}$ Clinic of Cardiac Surgery,Hospital Homolka, Prague \\ c Clinic of Cardiac Surgery, $2^{\text {nd }}$ Medical Faculty, Charles University, Faculty Hospital Motol, Prague \\ ${ }^{d}$ Clinic of Internal Medicine, $2^{\text {nd }}$ Medical Faculty, Charles University, Faculty Hospital Motol, Prague \\ e-mail: kotaska@email.cz
}

Received: April 7, 2006; Accepted: May 28, 2006

Key words: Brain natriuretic peptides/BNP, NT-proBNP/Left ventricular dysfunction/Left ventricular ejection fraction

We investigated the performance of brain natriuretic peptides (BNP and NT-proBNP) in detecting various degrees of left ventricular systolic dysfunction. The NT-proBNP assay (Roche) and the BNP assay (Bayer Shionoria) were performed in 46 patients (mean age 50 years; range 20-79 years) with various types of heart disease (chronic heart failure due to coronary artery disease, cardiomyopathy, acquired valve disease, congenital heart diseases) and different impairment of left ventricular systolic dysfunction was assessed by echocardiography. Patients were divided into four groups according to the left ventricular ejection fraction (LVEF) correlated with clinical severity. Significant differences in medians of NT-proBNP and BNP values between all groups were determined $(\mathrm{P}=0.0161$ for NT-proBNP and $\mathrm{P}=0.0180$ for BNP). For identifying patients with severe systolic dysfunction ( $\mathrm{LVEF}<40 \%$ ), receiver operating characteristic (ROC) analysis for both BNP and NT-proBNP was performed. The diagnostic performances expressed as areas under the curve were of 0.69 for NT-proBNP (cut off value $367 \mathrm{pg} / \mathrm{ml}$ ) and 0.60 for BNP (cut off value $172 \mathrm{pg} / \mathrm{ml}$ ). However, the BNP showed higher sensitivity ( $85 \%$ vs. $63 \%$ ) and a higher positive predictive value ( $69 \%$ vs $55 \%$ ) than the NT-proBNP. The negative predictive values of BNP and NT-proBNP were similar (70 \% and $71 \%$ respectively).

Brain natriuretic peptides are promising markers for the diagnosis of severe left ventricular systolic dysfunction.

\section{INTRODUCTION}

The natriuretic peptides BNP and N-terminal-proB$\mathrm{NP}$ are well established serum biomarkers for acute and chronic heart failure ${ }^{1-3}$. The prevalence of heart diseases increases markedly with age ${ }^{4}$ and early diagnosis of heart failure is crucial. It has been shown that treatment of patients with angiotensin-converting enzyme inhibitors or beta-blockers substantially delays disease progression ${ }^{5}$. Among all investigated neurohormones and natriuretic peptides, BNP and NT-proBNP are the best markers for ruling out left ventricular dysfunction ${ }^{2,6,7}$. Brain natriuretic peptides (BNPs) are secreted from the left ventricle at a rate proportional to the level of the wall stress of the ventricle $^{6,7}$. Theoretically, measuring of the $\mathrm{N}$-terminal cleavage product of the BNP precursor (NT-proBNP) may have analytical advantages over BNP due to the longer half-life and consequently higher plasma levels of NTproBNP in patients with left ventricular systolic dysfunction LVSD ${ }^{3}$. Furthermore, NT-proBNP is a stable peptide, which in whole blood can be analyzed 72 hours after the sample has been taken. Population-based studies (7-9) as well as studies in patients with acute dyspnoea in emergency departments (10-12) have shown that low levels of natriuretic peptides effectively rule out LVSD.
The study was designed to compare the usefulness of brain natriuretic peptides (NT-proBNP, BNP) in monitoring left ventricular impairment using commercially available automated NT-proBNP assay (Roche Diagnostic) and the BNP Assay (Bayer Shionoria).

\section{MATERIALS AND METHODS}

\section{Subjects}

Forty six patients ( 26 males, mean age 51 years, range 20-79 years; 20 females mean age 48 years, range $20-79$ years) with various forms of cardiovascular disease and different types of left ventricular impairment were selected for the study.

Consecutive ambulatory patients with clinically suspected left ventricular dysfunction were previously examined by echocardiography in specialized cardiologic departments. Echocardiography assessed clinically relevant indices such as left ventricular ejection fraction (LVEF), regional systolic left ventricular dysfunction, diastolic function, left ventricular mass and systolic pulmonary artery pressure.

The patients were divided into four groups according to the severity of the ventricular impairment based on 
Table 1. The clinical characteristics of the patients.

\begin{tabular}{|c|c|c|c|c|}
\hline & 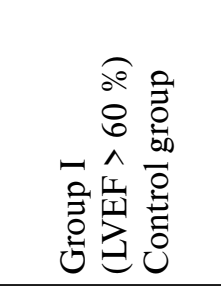 & 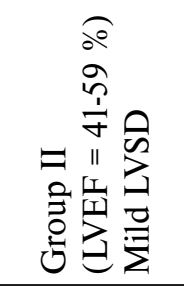 & 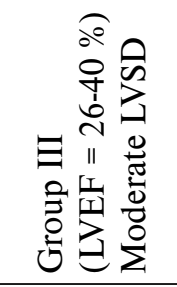 & 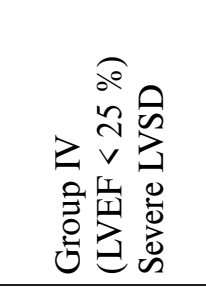 \\
\hline $\mathrm{N}$ & 18 & 9 & 10 & 9 \\
\hline Male & 8 & 6 & 7 & 5 \\
\hline Female & 10 & 3 & 3 & 4 \\
\hline LVEF (median + SD) & $62.2 \pm 2.6$ & $50 \pm 3.5$ & $35 \pm 4$ & $23.8 \pm 1.1$ \\
\hline BNP $($ median \pm SEM $)(\mathrm{pg} / \mathrm{ml})$ & $94.6 \pm 33.7$ & $31.8 \pm 27.2$ & $40.9 \pm 37.1$ & $181.0 \pm 159.9$ \\
\hline NT-proBNP $($ median \pm SEM $)(\mathrm{pg} / \mathrm{ml})$ & $299.4 \pm 122.0$ & $251.3 \pm 212$ & $394 \pm 281$ & $2085 \pm 1655$ \\
\hline History of AIM (\%) & $1(6)$ & $1(11)$ & $5(50)$ & $5(56)$ \\
\hline Hypertension (\%) & $6(33)$ & $4(44)$ & $4(40)$ & $4(44)$ \\
\hline $\begin{array}{l}\text { Systolic pressure }[\mathrm{mm} \mathrm{Hg}](\text { mean } \pm \mathrm{SD}) \\
\text { Diastolic pressure }[\mathrm{mm} \mathrm{Hg}](\text { mean } \pm \mathrm{SD})\end{array}$ & $\begin{array}{c}125 \pm 19 \\
75 \pm 12\end{array}$ & $\begin{array}{c}134 \pm 15 \\
78 \pm 11\end{array}$ & $\begin{array}{l}126.5 \pm 23 \\
80 \pm 13\end{array}$ & $\begin{array}{c}132 \pm 19 \\
78 \pm 16\end{array}$ \\
\hline $\begin{array}{l}\text { ACE inhibitors (\%) } \\
\text { Angiotensin inhibitors (\%) } \\
\text { Beta blockers (\%) } \\
\text { Diuretics (\%) }\end{array}$ & $\begin{array}{l}1(6) \\
1(6) \\
1(6) \\
2(12) \\
\end{array}$ & $\begin{array}{l}4(44) \\
1(11) \\
5(56) \\
4(44) \\
\end{array}$ & $\begin{array}{l}6(60) \\
1(10) \\
6(60) \\
5(50) \\
\end{array}$ & $\begin{array}{c}7(78) \\
0 \\
7(78) \\
6(67) \\
\end{array}$ \\
\hline Creatinine $[\mu \mathrm{mol} / 1]($ mean $\pm \mathrm{SD})$ & $80.5+16$ & $86.7 \pm 7$ & $89+22.5$ & $118.6 \pm 46.3$ \\
\hline Coronary artery disease & $1(6)$ & $4(44)$ & $4(40)$ & $5(56)$ \\
\hline Ebstein anomaly & 0 & $1(11)$ & $1(10)$ & 0 \\
\hline Ventricular septal defect & 0 & $1(11)$ & $1(10)$ & 0 \\
\hline Atrial septal defect & $8(44)$ & 0 & 0 & 0 \\
\hline Acquired aortic or mitral valve disease & $4(22)$ & $1(11)$ & $1(10)$ & 0 \\
\hline $\begin{array}{l}\text { Dilated cardiomyopathy including isolated } \\
\text { left ventricular noncompaction }\end{array}$ & 0 & 0 & $3(30)$ & 0 \\
\hline $\begin{array}{l}\text { Tricuspid atresia and complex cyanotic } \\
\text { congenital heart disease }\end{array}$ & 0 & $1(11)$ & 0 & $1(11)$ \\
\hline Corrected transposition of the great arteries & $1(6)$ & 0 & 0 & $1(11)$ \\
\hline Eisenmenger syndrome & 0 & 0 & $1(10)$ & 0 \\
\hline Anomalous left coronary artery origin & 0 & 0 & $1(10)$ & 0 \\
\hline $\begin{array}{l}\text { Transposition of great arteries } \\
\text { (Mustard correction) }\end{array}$ & 0 & 0 & 0 & $1(11)$ \\
\hline
\end{tabular}

Table 2. Predictive values and analytical parameters of brain natriuretic peptides (BNP, NT-proBNP) in patients with left ventricular systolic dysfunction.

\begin{tabular}{|c|c|}
\hline NT-proBNP $($ Cut off value $=\mathbf{3 6 7} \mathbf{~ p g} / \mathbf{m l})$ & BNP $($ Cut off value $=\mathbf{1 7 2} \mathbf{~ p g} / \mathbf{m l})$ \\
\hline PPV $55 \%$ & PPV $69 \%$ \\
\hline NPV $71 \%$ & NPV $70 \%$ \\
\hline Sensitivity $63 \%$ & Sensitivity $85 \%$ \\
\hline Specificity $63 \%$ & Specificity $45 \%$ \\
\hline
\end{tabular}

PPV - positive predictive value

NPV - negative predictive value

The cut off values for brain natriuretic peptides $(\mathrm{BNP}=172 \mathrm{pg} / \mathrm{ml}$, NT-proBNP $=367 \mathrm{pg} / \mathrm{ml})$ were assigned at the levels of maximal specificity and maximal sensitivity. 
the following criteria: Severe ventricular dysfunction was defined as LVEF $\leq 25 \%$ (9 patients), moderate LVSD was defined as a LVEF of $26-40 \%$ (10 patients), mild systolic ventricular dysfunction was defined as LVEF 41-59\% (9 patients). Eighteen patiens with LVEF $\geq 60 \%$ were taken as the control group. The clinical characteristics of the patients are listed in Tab. 1.

\section{Methods}

Serum and plasma samples were frozen immediately and kept at $-20{ }^{\circ} \mathrm{C}$ until BNP and NT-proBNP were analyzed. Serum levels of NT-proBNP were measured using commercially available electrochemiluminescence sandwich immunoassay (ECLIA, Roche) on an Elecsys System 2010. Plasma BNP levels were measured using commercially available immunochemiluminescence immunoassay (Shionoria BNP, Bayer) on an ADVIA Centaur System.

\section{Statistical analysis}

Differences in NT-pro BNP and BNP concentrations between subgroups were tested for statistical significance, either by the nonparametric Tukey multiple comparison test if the values were not normally distributed, or by the unpaired t-test and one-way analysis of variance (ANOVA) with multiple comparison tests (Neumann-Keuls multiple comparison test). A value of $p<0.05$ was considered as statistically significant. Receiver operating characteristic (ROC) analysis was performed to assess the diagnostic performance (by calculating the area under the ROC curve) of NT-proBNP and BNP to recognize patients with severe and mild left ventricular dysfunction arising from different cardiac pathologies. All data in the paper are expressed as median \pm SEM.

\section{RESULTS}

\section{NT - proBNP and left ventricular impairment}

Significant differences in the medians of NT-proBNP between all groups were determined ( $\mathrm{P}=0.0161$; One-way analysis of variance). NT-proBNP values increased with the severity of ventricular impairment, with the strongest

Fig. 1a, b: Concentration of NT-proBNP and BNP in patients with heart failure according to various types of left ventricular dysfunction

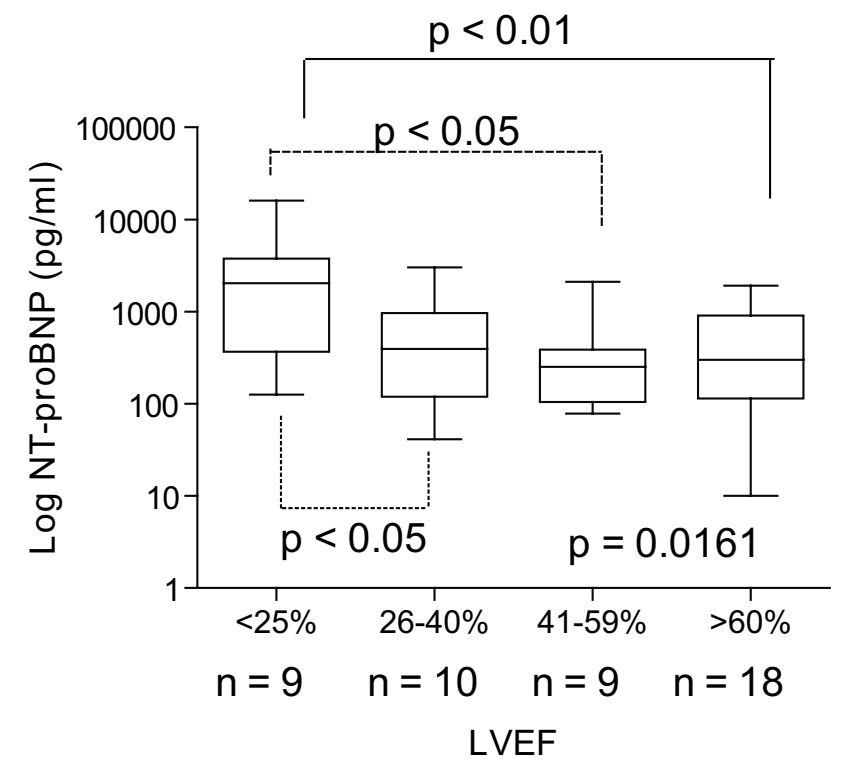

Fig. 1a: NT-proBNP

Data are presented as box (median, $25^{\text {th }}$ and $75^{\text {th }}$ percentiles) and whisker (higher and lower values) plots, significant difference between all groups are expressed as $\mathrm{p}=0.0161$

Significant differences between patients with severe dysfunction ( $\mathrm{LVEF}<25 \%$ ) and control group (LVEF > $60 \%$ ) are expressed as $\mathrm{p}<0.01$.

Significant differences between patients with severe dysfunction (LVEF $<25 \%$ ) and mild LVSD ( LVEF $=41-$ $59 \%)$ are expressed as $\mathrm{p}<0.05$.

Significant differences between patients with severe dysfunction $(\mathrm{LVEF}<25 \%)$ and moderate LVSD (LVEF = $26-40 \%)$.

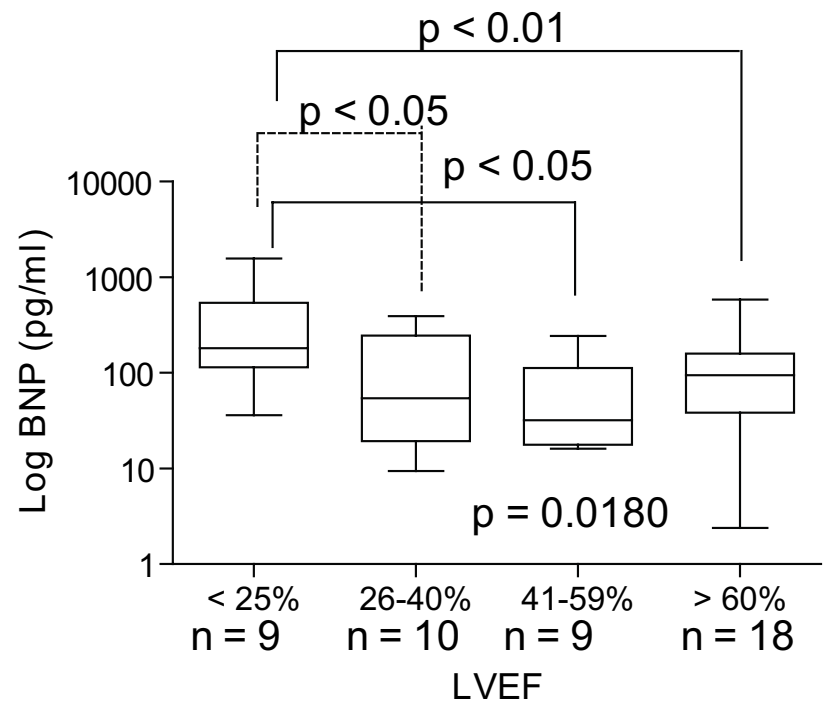

Fig. 1b: BNP

Data are presented as box (median, $25^{\text {th }}$ and $75^{\text {th }}$ percentiles) and whisker (higher and lower values) plots, significant difference between all groups are expressed as $\mathrm{p}=0.0180$

Significant differences between patients with severe dysfunction (LVEF $<25 \%$ ) and control group (LVEF > $60 \%$ ) are expressed as $\mathrm{p}<0.01$.

Significant differences between patients with severe dysfunction ( $\mathrm{LVEF}<25 \%$ ) and mild LVSD ( LVEF $=41-$ $59 \%$ ) are expressed as $\mathrm{p}<0.05$.

Significant differences between patients with severe dysfunction (LVEF $<25 \%$ ) and moderate LVSD (LVEF = $26-40 \%)$ are expressed as $p<0.05$. 
Fig. 2. ROC analysis of natriuretic peptides.

BNP: $\mathrm{AUC}=0.60 ; 95 \% \mathrm{CI}=(0.43-0.77), \mathrm{p}=0.23$

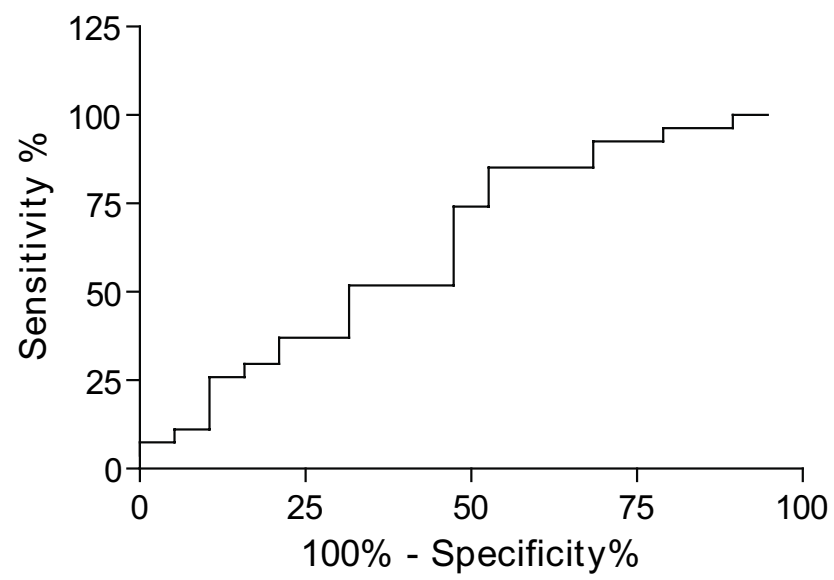

NT-proBNP: $\mathrm{AUC}=0.69 ; 95 \% \mathrm{CI}=(0.53-0.85), \mathrm{p}=0.03$

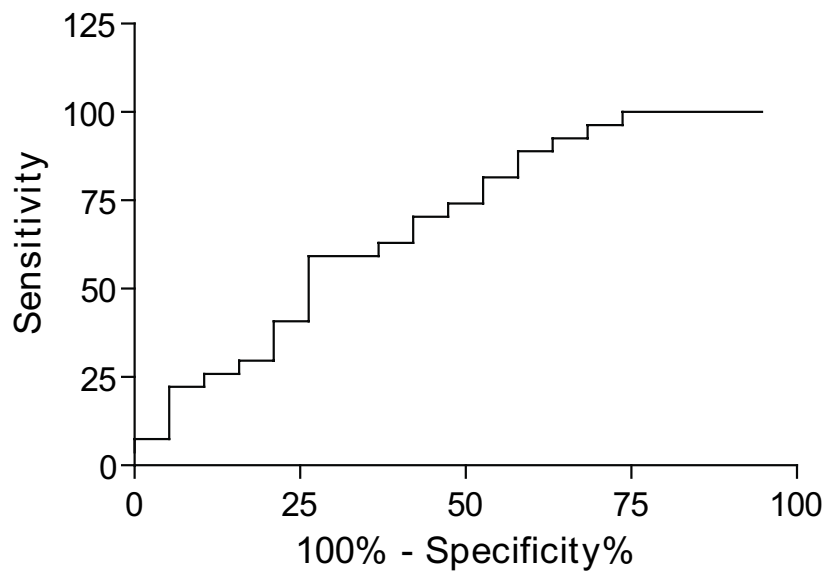

AUC - Area under the curve; CI - confidence interval

Receiver operating characteristic (ROC) analysis was performed to identify patients with severe systolic dysfunction ( $\mathrm{LVEF}<40 \%$ ). The diagnostic performance of natriuretic peptides is expressed as a calculation of AUC level.

difference between patients with severe ventricular impairment ( $\mathrm{LVEF}<25 \%$ ) and the control group (LVEF $>60 \%)(\mathrm{P}<0.01$; Newmann-Keuls multiple comparison test). Significant differences were found between patients with LVEF $<25 \%$ and patients with moderate ventricular impairment $(\mathrm{LVEF}=26-40 \%)$ and mild ventricular impairment $(\mathrm{LVEF}=41-60 \%)(\mathrm{P}<0.05$; Newmann-Keuls multiple comparison test) (Fig. 1a).

\section{BNP and left ventricular impairment}

Significant differences in the medians of BNP between all groups were determined $(\mathrm{P}=0.0180$; One-way analysis of variance). BNP values increased with the severity of left ventricular impairment, with the strongest difference between patients with severe LVSD (LVEF < $25 \%$ ) and the control group (LVEF $>60 \%)(\mathrm{P}<0.01$; NewmannKeuls multiple comparison test) (Fig. 1b).

\section{Discrimination of severity of left ventricular impairment.}

The ratio of $\mathrm{LVEF}=40 \%$ was assessed to distinguish the severe and mild ventricular dysfunction. ROC analysis showed different diagnostic performance for BNP and NT-proBNP (AUC $=0.60$ and 0.69 , respectively). The cut off values of natriuretic peptides for the diagnosis of left ventricular systolic dysfunction were $367 \mathrm{pg} / \mathrm{ml}$ for NT-proBNP and $172 \mathrm{pg} / \mathrm{ml}$ for BNP. BNP showed higher sensitivity than NT-proBNP ( $85 \%$ vs. $63 \%$ ). In contrast, NT-proBNP showed higher specificity (62\% vs. $45 \%$ ) (Fig. 2). BNP showed a higher positive predictive value (PPV) than NT-proBNP (69\% vs. $55 \%$ ). The negative predictive values of both BNP and NT-proBNP were similar ( $70 \%$ and $71 \%$, respectively). A summary of the analytical parameters and predictive values is listed in Tab. 2.

\section{DISCUSSION}

To date, several studies on the use of natriuretic peptides for detecting left ventricular dysfunction in selected patient groups have been performed and other studies have shown relationship between the concentrations of natriuretic peptides and severity of heart failure. ${ }^{1-3,5,13}$ In agreement with previous studies ${ }^{1-3,5,13}$, the levels of natriuretic peptides increased with the severity of the left ventricular impairment. As is known from the group analysis, NT pro-BNP and BNP show similar differences between various LVSD forms $(p=0.0161$ and $p=0.0180$, respectively).

The analysis of the area under the ROC curve of the current data suggests that NT-proBNP shows greater ability to discriminate patients with mild and severe left ventricular dysfunction, than the BNP did $(\mathrm{AUC}=0.69$ vs. 0.60). Nevertheless BNP gave higher sensitivity, lower specificity and higher positive predictive value than the NT-pro BNP ( $85 \%$ vs. $63 \%$; $45 \%$ vs. $63 \%$ and 69 $\%$ vs. $55 \%$ respectively). The negative predictive values for both natriuretic peptides were comparable (70 \% vs. $71 \%)$. Thus, BNP seems to be due to higher sensitivity and higher positive predictive value for accurate diagnosis of severe LVSD than the NT-proBNP. The cut-off values for NT-pro BNP and BNP assigned at the maximal specificity and maximal sensitivity were assessed at values of $367 \mathrm{pg} / \mathrm{ml}$ and $172 \mathrm{pg} / \mathrm{ml}$. The assessed cut-off values for NT-pro BNP and BNP do not differ significantly from the cut-off values presented in other studies presenting the cut-off values at the levels of $125-895 \mathrm{pg} / \mathrm{ml}$ for NT-proBNP ${ }^{14,15}$ and of $32-295 \mathrm{pg} / \mathrm{ml}$ for the BNP ${ }^{15,16}$ according to the age, gender, assay and diagnosis. The 
discrepancy in the cut-off values and modest AUC levels and negative predictive values found in our study for both natriuretic peptides are due to the fact, that other cardiac patients with normal ventricular systolic function (LVEF $>60 \%$ ) were taken as a control group. Nevertheless other diagnostic performances (specificity and sensitivity) for both natriuretic peptides are comparable with other studies monitoring various forms of left ventricular systolic dysfunction ${ }^{16-18}$.

One possible reason for the lower sensitivity of NTproBNP seen in our study is the higher rate of drug treatment. In the current study, the number of patients receiving contemporary heart failure treatment was high, 36 of 46 (78 \%) patients were treated using ACE inhibitors, beta-blockers, angiotensin inhibitors or diuretics. Drug treatment may decrease the accuracy of the peptides in detecting LVSD $^{19}$. In the present study, a diagnosis of moderate to severe LVSD was made in 19 patients (41\%); thus, in the present study population, approximately 2-3 echocardiograms were required to detect one patient with LVSD. These results differ from previously reported results showing 5,6 , or 10 echocardiograms per LVSD $\operatorname{diagnosis}^{20,21}$.

The advantage of using natriuretic peptides is to screen a large number of patients at risk of LVSD. This would allow patients with LVSD who have less classical symptoms as well as asymptomatic high-risk patients to be identified and in turn referred for echocardiographic evaluation and treatment.

\section{CONCLUSION}

Our findings confirmed that the measurement of brain natriuretic peptides is useful and relevant in the diagnosis of various types of cardiovascular diseases, including congenital heart diseases. However, due to the small study population, these results have to be regarded as preliminary. Thus, further clinical and laboratory investigations are needed to confirm the findings.

\section{LIST OF ABBREVIATIONS}

ACE - angiotensin converting enzyme

AUC - area under the curve

CI - confidence interval

BNP - brain natriuretic peptide

NT-proBNP N-terminal pro brain natriuretic peptide

NPV - negative predictive value

PPV - positive predictive value

LVSD - left ventricular systolic dysfunction

LVEF - left ventricular ejection fraction

\section{ACKNOWLEDGEMENT}

This study was supported by a research grant from the Ministry of Health MZO 00064203-6306.

\section{REFERENCES}

1. Seino Y, Ogawa A, Yamashita T et al. (2004) Application of NTproBNP and BNP measurements in cardiac care: a more discerning marker for the detection and evaluation of heart failure. Eur $\mathrm{J}$ Heart Fail 6, 295-300.

2. Hammerer-Lercher A, Neubauer E, Muller S, Pachinger O, Puschendorf B, Mair J.(2001) Head-to-head comparison of N-terminal pro-brain natriuretic peptide, brain natriuretic peptide and $\mathrm{N}$ terminal pro-atrial natriuretic peptide in diagnosing left ventricular dysfunction. Clin Chim Acta 310,193-197.

3. Hunt PJ, Richards AM, Nicholls MG, Yandle TG, Doughty RN, Espiner EA.(1997) Immunoreactive amino-terminal pro-brain natriuretic peptide (NT-PROBNP): a new marker of cardiac impairment. Clin Endocrinol (Oxf) 47,287-296.

4. Mair J, Friedl W, Thomas S, Puschendorf B. (1999) Natriuretic peptides in assessment of left-ventricular dysfunction. Scand J Clin Lab Invest Suppl 230,132-142.

5. McGeoch G, Lainchbury J, Town GI, Toop L, Espiner E, Richards AM. (2002) Plasma brain natriuretic peptide after long-term treatment for heart failure in general practice. Eur J Heart Fail 4,479483.

6. Yamamoto K, Burnett JC, Jr., Jougasaki M et al. (1996) Superiority of brain natriuretic peptide as a hormonal marker of ventricular systolic and diastolic dysfunction and ventricular hypertrophy. Hypertension 28, 988-994.

7. de Lemos JA, McGuire DK, Drazner MH. (2003) B-type natriuretic peptide in cardiovascular disease. Lancet 362, 316-322.

8. Hunt PJ, Espiner EA, Nicholls MG, Richards AM, Yandle TG. (1997) The role of the circulation in processing pro-brain natriuretic peptide (proBNP) to amino-terminal BNP and BNP-32. Peptides 18,1475-1481.

9. McDonagh TA, Robb SD, Murdoch DR et al. (1998) Biochemical detection of left-ventricular systolic dysfunction. Lancet 351, 913.

10. Maisel AS. (2001) Practical approaches to treating patients with acute decompensated heart failure. J Card Fail 2001;7:13-7.

11. Lainchbury JG, Campbell E, Frampton CM, Yandle TG, Nicholls MG, Richards AM.(2003) Brain natriuretic peptide and n-terminal brain natriuretic peptide in the diagnosis of heart failure in patients with acute shortness of breath. J Am Coll Cardiol 42,728-735.

12. Palladini G, Campana C, Klersy C et al. (2003) Serum N-terminal pro-brain natriuretic peptide is a sensitive marker of myocardial dysfunction in AL amyloidosis. Circulation 107, 2440-2445.

13. Almeida P, Azevedo A, Rodrigues R et al.(2003) B-type natriuretic peptide and left ventricular hypertrophy in hypertensive patients. Rev Port Cardiol 22, 327-336.

14. Gustafsson F, Steensgaard-Hansen F, Badskjaer J, Poulsen AH., Corell P, Hildebrandt P. (2005). Diagnostic and prognostic performance of N-terminal ProBNP in primary care patients with suspected heart failure. J Card Fail 11, S15-20.

15. Fonseca C, Sarmento PM, Minez A, Goncalves E, Covas R, Dias AR., Pina MJ, Ceia F. (2004). Comparative value of BNP and NT-proBNP in diagnosis of heart failure Rev Port Cardiol 23,979991.

16. Mueller T, Gegenhuber A, Poelz W, Haltmayer M. (2005). Diagnostic accuracy of B type natriuretic peptide and amino terminal proBNP in the emergency diagnosis of heart failure Heart 91, 606-612.

17. Hobbs FD, Davis RC, Roalfe AK, Hare R, Davies MK (2004). Reliability of N-terminal proBNP assay in diagnosis of left ventricular systolic dysfunction within representative and high risk populations Heart 90, 866-870.

18. Luchner A, Hengstenberg C, Lowel H, Buchner S, Schunkert H, Riegger, GA, Holmer S. (2005a). NT-ProBNP in outpatients after myocardial infarction: interaction between symptoms and left ventricular function and optimized cut-points J Card Fail 11, S21-27.

19. Murdoch DR, McDonagh TA, Byrne J et al. (1999) Titration of vasodilator therapy in chronic heart failure according to plasma brain natriuretic peptide concentration: randomized comparison 
of the hemodynamic and neuroendocrine effects of tailored versus empirical therapy. Am Heart J 138, 1126-1132.

20. Gustafsson F, Badskjaer J, Hansen FS, Poulsen AH, Hildebrant $\mathrm{P}$ (2003). Value of N-terminal proBNP in the diagnosis of left ventricular systolic dysfunction in primary care patients referred for echocardiography. Heart Drug 3, 141-146.

21. Nielsen OW, Hilden J, Larsen CT, Hansen JF (2001) Cross sectional study estimating prevalence of heart failure and left ventricular systolic dysfunction in community patients at risk. Heart 86, 172-178. 